\title{
Nanoporous polymer-based composites for enhanced hydrogen storage
}

\author{
Mi Tian ${ }^{1} \cdot$ Sébastien Rochat ${ }^{2} \cdot K_{\text {Katarzyna Polak-Kraśna }}^{3} \cdot$ Leighton T. Holyfield $^{1}$ - Andrew D. Burrows ${ }^{2}$. \\ Christopher R. Bowen ${ }^{3}$. Timothy J. Mays ${ }^{1}$ (])
}

Received: 24 December 2018 / Revised: 17 March 2019 / Accepted: 18 March 2019 / Published online: 10 May 2019

(c) The Author(s) 2019

\begin{abstract}
The exploration and evaluation of new composites possessing both processability and enhanced hydrogen storage capacity are of significant interest for onboard hydrogen storage systems and fuel cell based electric vehicle development. Here we demonstrate the fabrication of composite membranes with sufficient mechanical properties for enhanced hydrogen storage that are based on a polymer of intrinsic microporosity (PIM-1) matrix containing nano-sized fillers: activated carbon (AX21) or metal-organic framework (MIL-101). This is one of the first comparative studies of different composite systems for hydrogen storage and, in addition, the first detailed evaluation of the diffusion kinetics of hydrogen in polymer-based nanoporous composites. The composite films were characterised by surface area and porosity analysis, hydrogen adsorption measurements, mechanical testing and gas adsorption modelling. The PIM-1/AX21 composite with $60 \mathrm{wt} \%$ AX21 provides enhanced hydrogen adsorption kinetics and a total hydrogen storage capacity of up to $9.35 \mathrm{wt} \%$ at $77 \mathrm{~K}$; this is superior to the US Department of Energy hydrogen storage target. Tensile testing indicates that the ultimate stress and strain of PIM-1/ AX21 are higher than those of the MIL-101 or PAF-1 containing composites, and are sufficient for use in hydrogen storage tanks. The data presented provides new insights into both the design and characterisation methods of polymer-based composite membranes. Our nanoporous polymer-based composites offer advantages over powders in terms of safety, handling and practical manufacturing, with potential for hydrogen storage applications either as means of increasing storage or decreasing operating pressures in high-pressure hydrogen storage tanks.
\end{abstract}

Keywords Polymer of intrinsic microporosity $\cdot$ Nano-composite membrane $\cdot$ Hydrogen storage $\cdot$ Mechanical properties Hydrogen adsorption kinetics

\section{Introduction}

This article belongs to S.I. ISSHAC10, but it reach the press at the time the special issue was published.

Electronic supplementary material The online version of this article (https://doi.org/10.1007/s10450-019-00065-x) contains supplementary material, which is available to authorized users.

Timothy J. Mays

T.J.Mays@bath.ac.uk

1 Department of Chemical Engineering, University of Bath, Claverton Down, Bath BA2 7AY, UK

2 Department of Chemistry, University of Bath, Claverton Down, Bath BA2 7AY, UK

3 Department of Mechanical Engineering, University of Bath, Claverton Down, Bath BA2 7AY, UK
Concerns over diminishing and dispersing resources and the environmental impact of burning fossil fuels have driven attention to the development of alternative and sustainable energy sources and to the management of intermittent renewable energies. Hydrogen $\left(\mathrm{H}_{2}\right)$ produced from renewable resources has been considered as an important energy storage vector to fully exploit the benefits of renewable energies. Hydrogen has a high gravimetric energy density of $142 \mathrm{MJ} \mathrm{kg}^{-1}$ (higher heating value, HHV) (Bimbo et al. 2013), which is three times that of gasoline or diesel $\left(\sim 45 \mathrm{MJ} \mathrm{kg}^{-1}, \mathrm{HHV}\right)$, and it can be used to generate energy in internal combustion engines or in fuel cells, where water is the only by-product. However, hydrogen has a low volumetric energy density, making its storage a key challenge in the development of any future hydrogen-based economy. 
The current industry standard for storage is compressed gas at $70 \mathrm{MPa}$ and ambient temperature. However, this method comes with compression losses, and requires lightweight, mechanically strong and expensive containment materials to ensure safe operation.

One of the alternatives to compression is to store hydrogen by adsorption, which uses porous materials to densify hydrogen via enhanced interactions between the $\mathrm{H}_{2}$ molecules and internal surfaces. This research approach is well developed, and a number of different high-surface area materials have been discovered or created, that have potential as hydrogen storage materials, such as activated carbons (Bimbo et al. 2013; Tian et al. 2013), metal-organic frameworks (MOFs) (Naeem et al. 2016; Noguera-Díaz et al. 2016) and porous polymers (Rochat et al. 2017; PolakKraśna et al. 2017). However, the majority of materials developed for this purpose are tailored with solely hydrogen uptake in mind, which can cause issues when the focus of development shifts from small-scale laboratory tests to the full hydrogen tank scale. One adsorbent that exhibits a range of useful engineering properties for large-scale applications, such as good thermal stability and solution processability, is the polymer of intrinsic microporosity PIM-1 (Rochat et al. 2017; Budd et al. 2004a, b; Low et al. 2018). This material can be processed into a number of morphologies while remaining highly porous and exhibits good thermal and mechanical properties. However, the adsorption capacity of PIM-1 is rather limited, with a BET surface area $\left(\mathrm{N}_{2}\right.$ at $77 \mathrm{~K}$ ) generally reported in the $500-800 \mathrm{~m}^{2} \mathrm{~g}^{-1}$ range, and a hydrogen uptake of $0.5-1.1 \mathrm{wt} \%$ at $77 \mathrm{~K}$ and $0.1 \mathrm{MPa}$ (Rochat et al. 2017). In this work, we mix highly porous fillers into the PIM-1 matrix to form composite films and demonstrate that they have enhanced porosity and hydrogen storage properties. The introduction of additional high surface area nanoporous fillers into PIM-1 provides composites with enhanced performance in terms of surface area, porosity and gas adsorption capacity, while retaining processability and flexibility. It has also been reported that additives in PIM-based composites improve their long term structural stability (Low et al. 2018; Rochat et al. 2018).

To form efficient composite films with enhanced porosity, storage performance and mechanical properties for use in storage tanks, it is essential to identify suitable high surface area, divided nanoporous fillers that are compatible with the polymer matrix. Prompted by our previous work on PIM-1/PAF-1 composites for enhanced hydrogen storage (Rochat et al. 2017), we selected examples from three classes of nanoporous fillers-an activated carbon, a MOF and a porous organic polymer - with good hydrogen storage properties; and we evaluate the hydrogen adsorption kinetics of these new composite materials.

In order to understand the impact of different fillers on both hydrogen adsorption capacity and kinetics, we produced a range of PIM-1-based self-standing composite films with increasing weight concentration of the three selected nanoporous fillers (a pore size of $<2 \mathrm{~nm}$ ). Activated carbon is a classic porous material that has been widely used in many industrial processes including gas adsorption, separations and water treatment due to its high stability, high adsorption capability and low cost. Here we select a commercially available activated carbon material, $\mathrm{AX} 21$, which has been well studied and understood in our group (Ting et al. 2015; Bimbo et al. 2016), as a reference or a benchmark for other more complicated composite systems. PIM-1/PAF-1 composites for hydrogen storage have been reported recently (Rochat et al. 2017), and we demonstrated that the stable and processable PIM-1/PAF-1 composite membranes possess enhanced hydrogen storage performance and sufficient mechanical properties for integration into high-pressure hydrogen storage tanks. MOFs have been widely studied as fillers in mixed matrix membranes for gas separation (Ghalei et al. 2017). The nanoporous structure of MOFs can be tuned to specific applications and the organic linkers provide a stronger interaction with polymer chains, resulting in a better compatibility between the MOF and the polymer matrix ( $\mathrm{Lin}$ et al. 2014). Here, we select $\left[\mathrm{Cr}_{3} \mathrm{O}(\mathrm{OH})\left(\mathrm{H}_{2} \mathrm{O}\right)_{2}(\mathrm{bdc})_{3}\right](\mathrm{MIL}-$ $101(\mathrm{Cr})$, referred to hereafter as MIL-101, bdc $=1,4$-benzenedicarboxylate) as a third type of nanoporous additive to form PIM-1/MIL-101 composite films. MIL-101 was selected due to its microporosity, relatively high hydrogen uptake, ease of synthesis and high stability.

Based on the density and porosity of the composites, we identify the critical volume percentage of nanoporous filler of the PIM-1 based composites, which we define as the point at which a composite fails to form a self-standing film. This critical volume can be used to determine the limitations of polymer-based composites and their functions; for example, as a coherent liner in a high-pressure hydrogen storage tank (Rochat et al. 2017). Low and high-pressure hydrogen uptake measurements were performed to evaluate hydrogen storage capacities of the composites, which in some cases potentially meet the US Department of Energy (DoE) hydrogen storage target (Target Explanation Document 2017). The kinetics of hydrogen adsorption of the pure materials and the composites were studied through mathematical modelling, indicating significantly faster hydrogen diffusion kinetics in PIM-1 films after introduction of nanoporous fillers. The mechanical properties of the composites were also investigated in order to fully assess their potential for use in storage applications and determine their ultimate properties. The significance of these studies reaches beyond the immediate interest in hydrogen storage and will provide new insights into the practical search for high-pressure hydrogen storage tank systems. In addition, this study provides a new design strategy for the selection and analysis of nanoporous fillers in polymer matrices using a broad range of characterisation 
techniques, including mechanical testing, high-pressure gas adsorption and kinetics investigations.

\section{Results and discussion}

PIM-1 and MIL-101(Cr) were synthesised following published procedures and characterised by $\mathrm{N}_{2}$ adsorption at $77 \mathrm{~K}$ and X-ray powder diffraction (PXRD) (Budd et al. 2004; Férey et al. 2005; Jiang et al. 2012). The PIM-1 sample used for the fabrication of composite films with AX21 and MIL-101 was determined to have a BET surface area of $724 \mathrm{~m}^{2} \mathrm{~g}^{-1}$ from $\mathrm{N}_{2}$ adsorption at $77 \mathrm{~K}$. This was in good agreement with prior literature values (Budd et al. 2004), but slightly lower than the surface area of the PIM-1 that was used for PIM-1/PAF-1 composite films (Rochat et al. 2017; Polak-Kraśna et al. 2017).

The PXRD patterns of the synthesised MIL-101 powder, PIM-1 film and the PIM-1/MIL-101 composite films in Fig. S1 compare well with previous studies of pure PIM-1 (Wang et al. 2014) and pure MIL-101 (Férey et al. 2005; Jiang et al. 2012). The composites, as expected, show a mixture of the patterns of PIM-1 and MIL-101. The composites, PIM1/10 wt\% MIL-101 (referred to as M10) and PIM-1/30 wt\% MIL-101 (referred to as M30), clearly show the strong MIL101 peaks in the $8-10^{\circ}$ range, which indicates that MIL101 was successfully embedded in films and has retained crystallinity.

The method to create PIM-1-based composite films was based on our previous experience with PIM-1/PAF-1 composites. As shown in Fig. 1, the nano-sized porous fillers (Fig. 1b) were dispersed into PIM-1 (Fig. 1a), leading to the formation of freestanding PIM-1-based composite films. With increasing weight concentration of filler, the

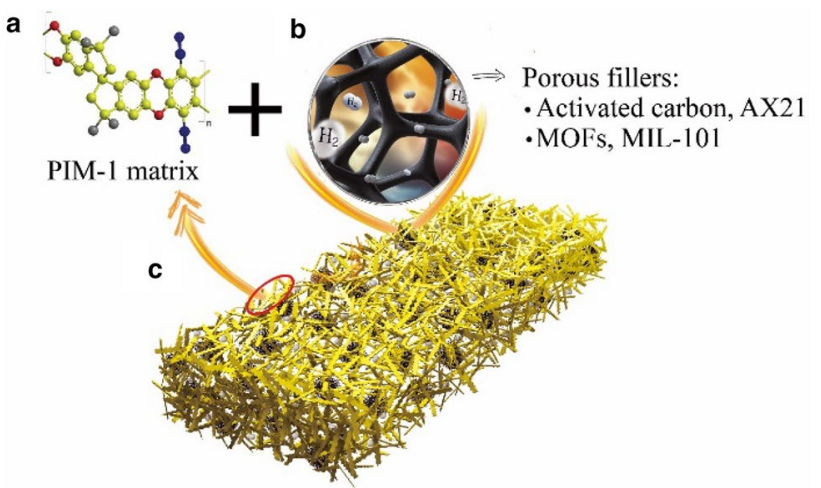

Fig. 1 a Schematic structure of the repeating kinked unit of PIM-1, showing the ladder-like carbon- (yellow) and oxygen-based skeleton (red) as well as nitrile (blue) and methyl (grey) side-chains. Hydrogen atoms have been removed for clarity, $\mathbf{b}$ the nanoporous fillers employed, $\mathbf{c}$ schematic representation of the PIM-1 based composites. (Color figure online) solvent-cast films were found to become increasingly brittle and tended to crack upon drying.

Images of the PIM-1/AX21 and PIM-1/MIL-101 composite films are shown in Fig. 2 and indicate that thin PIM1-based composite films were successfully produced. The transparency of the composite films decreased and the colour became darker with increasing fraction of the nanoporous fillers. The concentration of AX21 in the composite could be as high as $60 \mathrm{wt} \%$ in the film, while MIL-101 could not exceed $40 \mathrm{wt} \%$-as demonstrated in Fig. 2 where the $50 \mathrm{wt} \%$ PIM-1/MIL-101 composite failed to form a cohesive film. PIM-1/PAF-1 composites showed a similar tendency with a maximum loading of $37.5 \mathrm{wt} \%$ (Rochat et al. 2017). The PIM-1 with 10, 20, 30, 40, 50 and $60 \mathrm{wt} \%$ AX21 composites are referred to as A10, A20, A30, A40, A50 and A60 respectively. Applying the same principle to PIM-1/MIL101 composites, M10, M20 and M30 correspond to 10, 20 and $30 \mathrm{wt} \%$ MIL-101 in PIM-1 matrix.

One function of PIM-1 is to bind filler particles together in a composite membrane. The individual components of the composite materials possess a clear boundary/interface that is visible in the cross-sectional SEM images, Fig. 3, that resulted from the physical mixing of the additives and the polymer matrix. The octahedral MIL-101 crystals were well dispersed in the PIM-1 matrix, Fig. 3e, as previously reported for the PIM-1/PAF-1 composite (Rochat et al. 2017), while the larger 'rock-like' AX21 particles were located at the base of the composite film, Fig. 3b.

From the SEM images, Fig. S2, the particle sizes of MIL101 and PAF-1 were estimated to be $400 \mathrm{~nm}$ and $320 \mathrm{~nm}$ respectively, see Table 1, which was almost 15 times smaller than the particle size of AX21 $(5.57 \pm 0.36 \mu \mathrm{m})$. Furthermore, the density of AX21 proved to be greater than both MIL-101 and PAF-1, as shown in Table 1. Therefore, the larger and heavier carbon AX21 particles settled during solvent evaporation, and posed difficulties in forming flat and

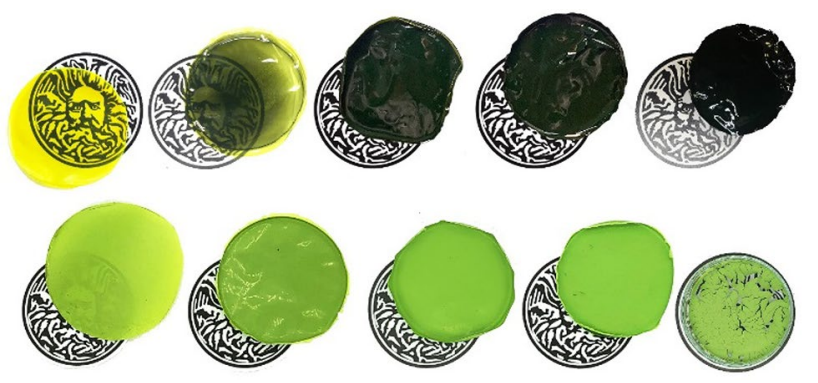

Fig. 2 Images of $6 \mathrm{~cm}$ diameter films, placed above the logo of the University of Bath to demonstrate varying transparency. Top rowleft to right: PIM-1/AX21 composites with AX21 weight concentration at $0 \%(\mathrm{~A} 0), 10 \%(\mathrm{~A} 10), 20 \%(\mathrm{~A} 20), 40 \%(\mathrm{~A} 40)$ and $60 \%(\mathrm{~A} 60)$. Bottom row-left to right: PIM-1/MIL-101 composites with MIL101 weight concentration at 10\% (M10), 20\% (M20), 30\% (M30), $40 \%$ (M40), and 50\% (M50) 


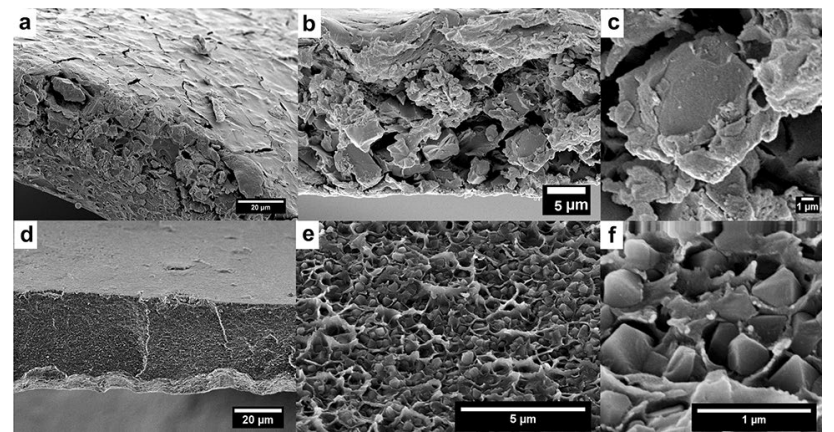

Fig. 3 SEM images of the cross-sections of $30 \mathrm{wt} \%$ PIM-1/AX21 composites (A30, images a-c) and cross-section of $30 \mathrm{wt} \%$ PIM-1/ MIL-101(M30, d-f)

Table 1 Summary of density and particle size of PIM-1, AX21, MIL101 and PAF-1

\begin{tabular}{lllll}
\hline & $\begin{array}{l}\text { Skeletal } \\
\text { density }(\mathrm{g} \\
\left.\mathrm{cm}^{-3}\right)^{\mathrm{a}}\end{array}$ & $\begin{array}{l}\text { Total pore } \\
\text { volume }\left(\mathrm{cm}^{3}\right. \\
\left.\mathrm{g}^{-1}\right)^{\mathrm{b}}\end{array}$ & $\begin{array}{l}\text { Bulk } \\
\text { density }(\mathrm{g} \\
\left.\mathrm{cm}^{-3}\right)^{\mathrm{c}}\end{array}$ & $\begin{array}{l}\text { Particle size } \\
(\mathrm{nm})^{\mathrm{d}}\end{array}$ \\
\hline PIM-1 & 1.13 & 0.40 & 0.78 & - \\
AX21 & 2.07 & 1.52 & 0.50 & $5570 \pm 360$ \\
MIL-101 & 1.12 & 1.49 & 0.42 & $405 \pm 38$ \\
PAF-1 & 1.25 & 2.03 & 0.35 & $320 \pm 95$ \\
\hline
\end{tabular}

${ }^{\text {a }}$ Determined from He pycnometry

${ }^{\mathrm{b}}$ Total pore volume determined by uptake at $\mathrm{p} / \mathrm{p}_{0}=0.97$ on $\mathrm{N}_{2}$ isotherms at $77 \mathrm{~K}$

${ }^{\mathrm{c}}$ Calculated from skeletal density and total pore volume via Eq. (1)

${ }^{\mathrm{d}}$ Particle size determined from SEM images using ImageJ software

well-controlled composite membranes. To solve this problem, we cast the PIM-1/AX21 composite membranes with a well-controlled slow evaporation process (approximately 2 weeks for the PIM-1/AX21 composite), which allowed the reorientation of polymer chains so that the polymer matrix provided improved support for the carbon particles (Kamata and Iyoda 2006).

Of the three different composite systems studied, PIM-1/ AX21 has the highest critical weight concentration-with a filler content of up to $60 \mathrm{wt} \%$-which allows the generation of composites with significantly enhanced surface area and related gas adsorption performance. To produce a general method of determining the limitation of the composite system, we employed the critical powder volume fraction to represent the maximum volume loading of powder in the composite system that yields a coherent membrane. To understand the distribution of nanoporous filler particles in the polymer matrix, we converted the weight concentration to volume fraction by dividing weight concentration by the bulk density of the composite. Figure 4 illustrates the corresponding critical weights of the three types of composites. It can be concluded from Fig. 4 that approximately 57-60 vol\%

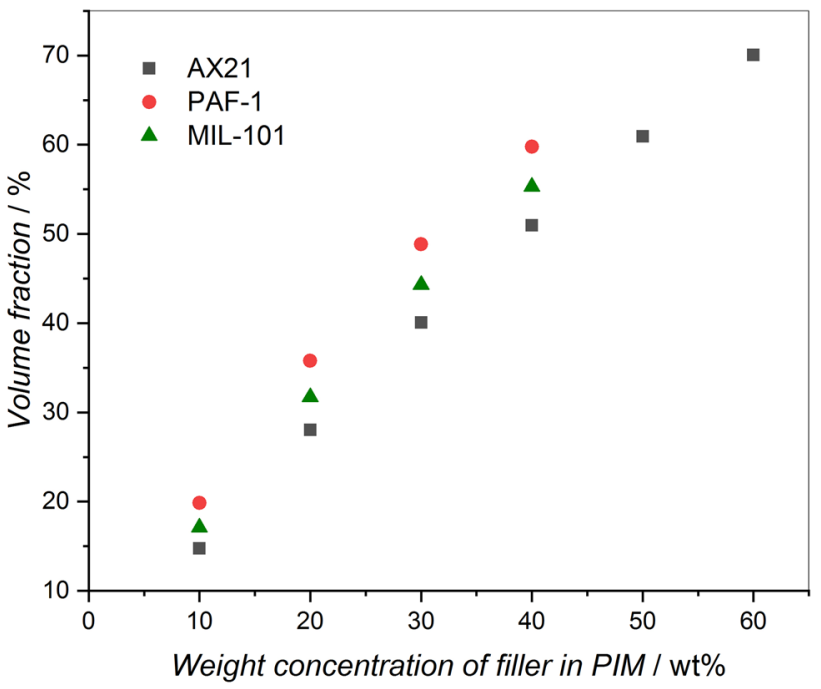

Fig. 4 Volume fraction versus weight concentration of the nanoporous fillers in the PIM-1 matrix

of filler is a critical volume of fillers to ensure the shape and physical structure of the composite system. When the volume percent of filler is above $60 \%$, PIM-1-based composites start to lose their processability. However, the critical volume percent of AX21 in the composite is higher, up to $60 \%$, compared to the MIL-101 and PAF-1 composites. This is possibly a result of the larger particle size and higher bulk density of AX21 particles (which is closer to the PIM-1 density) which enable stronger interactions, making AX21 the preferable choice of filler for this matrix. Interestingly, it has been reported that the percolation threshold for a threedimensional system is $1 / 3$, indicating that when the filler fraction is more than $67 \mathrm{vol} \%$ a fully connected polymer matrix is unlikely to form (Louis and Gokhale 1996).

\subsection{Surface area, porosity and low-pressure hydrogen adsorption measurements}

To evaluate the porosity of the prepared materials, $\mathrm{N}_{2}$ adsorption-desorption isotherms were measured, see Fig. 5. The isotherms displayed type I and type IV behaviours in the low and medium pressure ranges respectively. The $\mathrm{N}_{2}$ isotherms of MIL-101 and AX21 were fully reversible, as would be expected in a nanoporous material, indicating structural rigidity. The composites displayed significant hysteresis, as anticipated for PIM-1-based materials (McKeown and Budd 2006), due to narrow channels constricting mass transfer into larger micropores. The presence of MIL-101 and AX21 within PIM-1 (samples A30 and M30 are shown in Fig. 5) did not raise the rate of $\mathrm{N}_{2}$ mass transfer into the film, as indicated by the presence of similar hysteresis loops in the $\mathrm{N}_{2}$ isotherms of PIM-1, A30 and M30. BET surface areas, as a function of weight concentration of fillers in the 

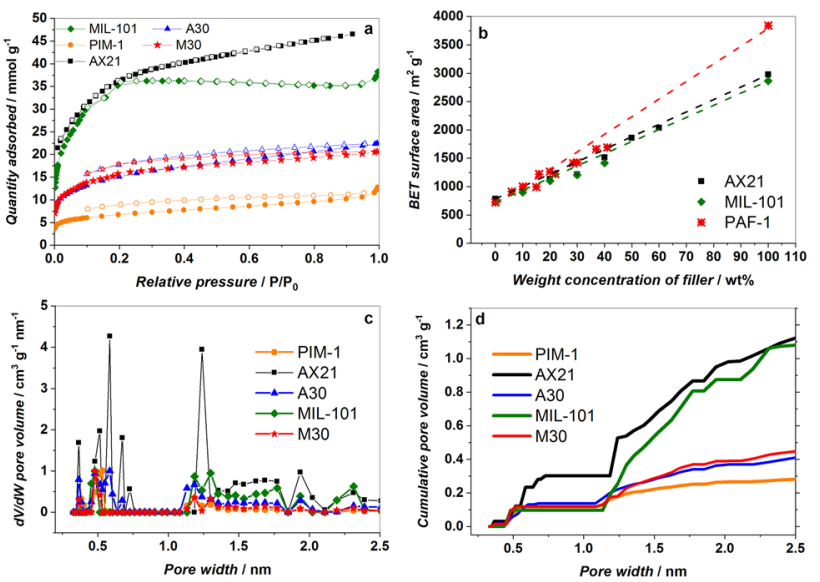

Fig. 5 a $\mathrm{N}_{2}$ isotherms of PIM-1 (orange circles), AX21 (black squares), MIL-101 (green diamonds), 30\% AX21 composite (A30, blue triangles) and 30\% MIL-101 composite (M30, red stars) measured at $77 \mathrm{~K}$. The solid filled symbols represent adsorption and the open symbols represent desorption. b BET surface area as a function of weight concentration of the fillers in PIM-1-based composites. c Micropore size distributions, and $\mathbf{d}$ cumulative pore volumes of PIM1, MIL-101, AX21 and the two composites, A30 and M30, as determined by NLDFT. (Color figure online)

samples shown in Fig. 5b, presented a clear linear trend for PIM-1/AX21 composites. This would be expected under a simple rule of mixtures-where properties of the composite are given by the weighted sum of the properties of its constituents - as represented by the dotted lines in Fig. 5b. The discrepancy from the rule of mixtures for the higher MOF content composites appears to imply that the full porosity of MIL-101 was not accessed. Our group previously reported, for the first time, this phenomenon for the PIM-1/PAF-1 composites, in which the surface area is slightly lower than predicted using the rule of mixtures (Rochat et al. 2017). The surface area of PIM-1/AX21 composites increases proportionally to the AX21 concentration, and follows the rule of mixtures well. This implies that the full porosity of AX21 in the composite system was maintained since their larger particle size leads to a reduced interface with the PIM-1 matrix. This, in turn, creates less disturbance in the polymer matrix and prevents pore blockage. The AX21 component in the composite played a leading role in the case of $\mathrm{N}_{2}$ adsorption-desorption isotherms since the physical properties of AX21 were well retained and less disturbed by the PIM-1 matrix.

On combining $\mathrm{N}_{2}$ isotherms at $77 \mathrm{~K}$ with $\mathrm{CO}_{2}$ adsorption isotherms at $273 \mathrm{~K}$, the micropore size distribution was analysed using nonlocal density functional theory (NLDFT), as illustrated in Fig. 5c, Figs. S3 and S4. As $\mathrm{N}_{2}$ molecules are unable to probe pores smaller than $0.36 \mathrm{~nm}, \mathrm{~N}_{2}$ adsorption is not ideal for probing microporosity, especially in the range of ultramicropores (pore widths $<0.7 \mathrm{~nm}$ ) (Thommes
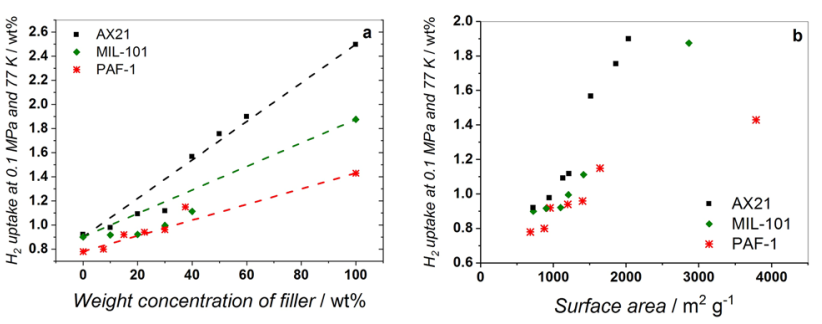

Fig. $6 \mathrm{a} \mathrm{H}_{2}$ uptake at up to $0.1 \mathrm{MPa}$ and $77 \mathrm{~K}$ as a function of weight concentration for AX21, MIL-101 and PAF-1; the dotted lines represent the theoretical "rule of mixtures" in PIM-1/AX21 (black), PIM-1/MIL-101 (green) and PIM-1/PAF-1 (red). b $\mathrm{H}_{2}$ uptake at to $0.1 \mathrm{MPa}$ and $77 \mathrm{~K}$ as a function of the BET surface area of the composites. Values related to PAF-1 composites are cited from our previous study (Rochat et al. 2017) for comparison. (Color figure online)

2010). $\mathrm{CO}_{2}$ adsorption at $273 \mathrm{~K}$ enables the diffusion of $\mathrm{CO}_{2}$ molecules into narrower pores that cannot be probed by $\mathrm{N}_{2}$ at $77 \mathrm{~K}$ (Thommes et al. 2015). The method of using the combined $\mathrm{N}_{2}$ isotherms at $77 \mathrm{~K}$ and $\mathrm{CO}_{2}$ isotherms at $273 \mathrm{~K}$ was able to cover the entire micropore size distribution, and pore sizes between 0.6 and $0.7 \mathrm{~nm}$ have been determined as optimal for $\mathrm{H}_{2}$ adsorption (Ting et al. 2015; Yushin et al. 2006). The pore size distribution of the PIM-1 film displayed a trimodal distribution with maxima at 0.38 , 0.53 and $1.19 \mathrm{~nm}$, and this is consistent with the slow $\mathrm{N}_{2}$ adsorption kinetics at $77 \mathrm{~K}$, illustrated by the long measurement time required for a complete $\mathrm{N}_{2}$ isotherm at $77 \mathrm{~K}$ of the PIM-1 film ( 3 days). AX21 and MIL-101 showed wider bimodal distributions in the pore size ranges of $0.3-0.6 \mathrm{~nm}$ and 1.1-2.0 $\mathrm{nm}$. The pore size distribution of the composites indicated a combined porous structure of the PIM-1 matrix and the fillers. From Fig. 5d, it can be noted that the cumulative pore volume of the MIL-101 and PIM-1/MIL-101 composites was maintained within the pore size range of $0.3-0.6 \mathrm{~nm}$ and is improved within the $1.1-1.5 \mathrm{~nm}$ range. The incorporation of AX21 in the PIM-1 matrix slightly increased the cumulative pore volumes in pores within the pore size range of $0.3-0.6 \mathrm{~nm}$ and notably enhanced the pore volume in pores within the range of 1.1-1.5 nm. By introducing nanoporous fillers, the modification of the porous structure of the PIM-1 film greatly influenced both its gas adsorption capacity and kinetics.

Hydrogen storage at low pressure up to $0.1 \mathrm{MPa}$ and $77 \mathrm{~K}$, which is directly correlated to the surface area of materials (Broom et al. 2016) was investigated (Figs. S5 and S6). Hydrogen uptake of the composites increased linearly with the weight concentration of AX21 and MIL-101, as shown in Fig. 6a alongside predictions from the rule of mixtures, which are indicated by the dotted lines. The difference between the rule of mixtures prediction and experimental results varies depending on the additive type and their concentration. The $\mathrm{H}_{2}$ uptake on the low concentration 
AX21 composites $(<30 \mathrm{wt} \%)$ is lower than predicted. As the concentration of AX21 increased (>30 wt \%), the hydrogen uptake generally followed or was even slightly higher than predicted by the rule of mixtures. This demonstrates that hydrogen appears to have difficulty in accessing the porosity in the pores under conditions that are unfavourable for mass transport, namely $77 \mathrm{~K}$ and low pressure. By increasing the AX21 weight concentration, however, these limitations could be overcome to allow hydrogen to access the full porosity of AX21, thus raising the effective capacity of the composite.

The $\mathrm{H}_{2}$ uptake of MIL-101 composites had lower $\mathrm{H}_{2}$ uptakes than predicted by the rule of mixture, which could be indicative of inaccessible porosity in the MIL-101, reinforcing the results from BET surface area analysis. The highest hydrogen uptake at $0.1 \mathrm{MPa}$ and $77 \mathrm{~K}$ was $1.9 \mathrm{wt} \%$ in the A60 sample, over 2.5 times greater than the uptake of the PIM-1 film alone (0.73 wt\%). AX21 composite films have also shown higher $\mathrm{H}_{2}$ adsorption capacity at equivalent surface areas at $0.1 \mathrm{MPa}$ and $77 \mathrm{~K}$, as illustrated in Fig. 6b. The AX21 composite film with a surface area of $\sim 1200 \mathrm{~m}^{2} \mathrm{~g}^{-1}$ adsorbed $1.12 \mathrm{wt} \% \mathrm{H}_{2}$, whereas the uptake of PAF-1 composite and MIL-101 composite at $\sim 1200 \mathrm{~m}^{2} \mathrm{~g}^{-1}$ was 1.00 and $0.94 \mathrm{wt} \%$ respectively. From Table 2, it can be seen that the micropore volume of the PIM-1/AX21 composite is higher than that of the PIM-1/MIL-101 composite at the same surface area level. This suggests that AX21 offers more favourable pore sizes and shapes to enhance hydrogen adsorption (Gogotsi et al. 2009).

\subsection{Mechanical properties and thermal stability of composite films}

Robust films of PIM-1/MIL-101 composites for mechanical testing were obtained with concentrations of $10 \mathrm{wt} \%$, $20 \mathrm{wt} \%$ and $30 \mathrm{wt} \%$ of MIL-101 in PIM-1. Samples containing higher concentrations of fillers were too brittle to enable casting of large enough films and preparing of test pieces suitable for mechanical testing. Ultimate stress and strain decreased with an increase in additive content while elasticity remained on a similar level, as shown in Fig. 7,
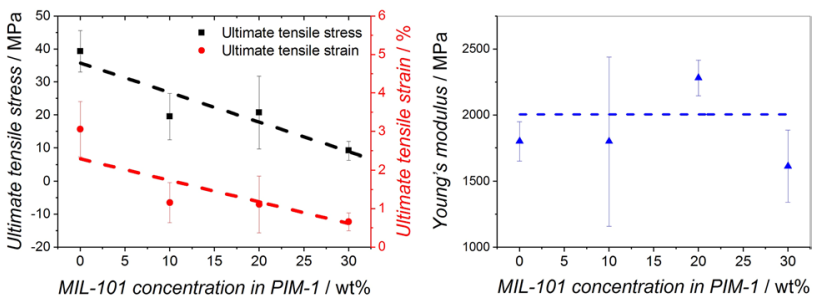

Fig. 7 Mechanical properties of PIM-1/MIL-101, PIM-1/AX21 and PIM-1/PAF-1 composite films, showing a ultimate tensile stress and b ultimate tensile strain as a function of weight concentration of filler in PIM-1. Values related to PAF-1 composites are cited from our previous study (Rochat et al. 2017) for comparison

Table 2 Surface area and hydrogen uptake analysis of the materials investigated in this study. See ESI for additional data

\begin{tabular}{|c|c|c|c|c|c|c|c|}
\hline \multirow[t]{2}{*}{ Sample } & \multirow[t]{2}{*}{$\begin{array}{l}\text { Filler concentra- } \\
\text { tion (wt } \%)\end{array}$} & \multirow[t]{2}{*}{$\begin{array}{l}\text { BET surface area } \\
\left(\mathrm{m}^{2} \mathrm{~g}^{-1}\right)^{\mathrm{a}}\end{array}$} & \multirow[t]{2}{*}{$\begin{array}{l}\text { Total pore volume } \\
\left(\mathrm{cm}^{3} \mathrm{~g}^{-1}\right)^{\mathrm{b}}\end{array}$} & \multirow[t]{2}{*}{$\begin{array}{l}\text { Micropore volume } \\
\left(\mathrm{cm}^{3} \mathrm{~g}^{-1}\right)\end{array}$} & \multirow[t]{2}{*}{$\begin{array}{l}\mathrm{H}_{2} \text { uptake at } 0.1 \mathrm{MPa} \\
\text { and } 77 \mathrm{~K}(\mathrm{wt} \%)\end{array}$} & \multicolumn{2}{|c|}{$\begin{array}{l}\text { Total } \mathrm{H}_{2} \text { uptake at } \\
10 \mathrm{MPa} \text { and } 77 \mathrm{~K}\end{array}$} \\
\hline & & & & & & $\overline{(w t \%)}$ & $\left(\mathrm{kg} \mathrm{m}^{-3}\right)$ \\
\hline \multicolumn{8}{|c|}{ PIM-1/AX21 } \\
\hline $\begin{array}{l}\text { PIM-1 } \\
\text { (A0) }\end{array}$ & 0 & 724 & 0.40 & 0.27 & 0.92 & 2.52 & 19.64 \\
\hline A10 & 10 & 944 & 0.66 & 0.30 & 0.98 & - & - \\
\hline A20 & 20 & 1130 & 0.70 & 0.37 & 1.09 & 3.70 & 26.80 \\
\hline $\mathrm{A} 30$ & 30 & 1215 & 0.77 & 0.41 & 1.12 & - & - \\
\hline A40 & 40 & 1513 & 0.97 & 0.46 & 1.57 & - & - \\
\hline A50 & 50 & 1860 & 1.08 & 0.64 & 1.76 & - & - \\
\hline A60 & 60 & 2034 & 1.22 & 0.71 & 1.90 & 6.36 & 38.95 \\
\hline $\mathrm{AX} 21$ & 100 & 2975 & 1.62 & 0.98 & 2.50 & 9.24 & 46.23 \\
\hline \multicolumn{8}{|c|}{ PIM-1/MIL-101 } \\
\hline M10 & 10 & 900 & 0.68 & 0.30 & 0.92 & 3.33 & 24.76 \\
\hline M20 & 20 & 1098 & 0.79 & 0.33 & 0.92 & 4.04 & 28.60 \\
\hline M30 & 30 & 1206 & 0.73 & 0.39 & 1.00 & 4.10 & 27.54 \\
\hline M40 & 40 & 1415 & 0.83 & & 1.11 & - & - \\
\hline MIL-101 & 100 & 2863 & 1.49 & 0.87 & 1.88 & 8.93 & 37.49 \\
\hline
\end{tabular}

${ }^{a}$ Determined from $\mathrm{N}_{2}$ isotherms at $77 \mathrm{~K}$

${ }^{\mathrm{b}}$ Total pore volume determined by uptake at $p / p_{0}=0.97$ on $\mathrm{N}_{2}$ isotherms at $77 \mathrm{~K}$ 
Tables S3 and S4. More details of mechanical testing on the composite films are listed in Figs. S8 and S9, including Young's modulus.

It was possible to manufacture films with higher concentration of additive using activated carbon AX21, reaching a concentration of $50 \mathrm{wt} \%$. We failed to make the PIM1/60 wt\% AX21 composite membrane in a $20 \mathrm{~cm}$ Petri dish as it was too brittle to be taken off, even though we achieved PIM-1/60 wt\% AX21 film on a small scale (6 cm Petri dish) for gas adsorption measurement. In both PIM-1/MIL-101 and PIM-1/AX21 composites, the tensile strength decreases with increasing additive contents. It was clear even during sample preparation that samples with higher MIL-101 content were more brittle and would crack easily during cutting of the samples, as compared to PIM-1/AX21 composites. The addition of fillers thus introduces structural imperfections that lead to a lower ultimate stress. The mechanical behaviour of PIM-1/MIL-101 composites is similar to those of PIM-1/PAF-1 (Rochat et al. 2017; Polak-Kraśna et al. 2017), and values of ultimate strain and stress obtained for highest available additive concentrations of $30 \mathrm{wt} \%$ are comparable. Young's modulus decreased significantly with higher AX21 content, unlike in case of MIL-101 where it remained at a similar level (Gogotsi et al. 2009). Additionally, Fig. S16 shows examples of fracture surfaces of composites with increasing weight fraction of filler that have been fractured by simple bending. The difference in Young's modulus between the polymer matrix and filler particulates can lead to poor stress transfer at the filler polymer interface and debonding of the polymer and filer particles. This is likely to be more prevalent at high filler concentrations where large agglomerates of filler particles can act as initiation site for failure, see Fig. S16d for $50 \mathrm{wt} \%$ AX21 in PIM-1 matrix, and drawing of the polymer matrix around the filler particles can be observed.

Thermogravimetric analysis (TGA) was performed in flowing, dry air up to $1000{ }^{\circ} \mathrm{C}$ (Fig. S7) at $5{ }^{\circ} \mathrm{C} \mathrm{min}^{-1} \mathrm{MIL}-$ 101 showed the lowest thermal stability, with a decomposition onset temperature of $175^{\circ} \mathrm{C}$. AX21 and PIM-1, however, started decomposing at $\sim 350{ }^{\circ} \mathrm{C}$, indicating better thermal stability under these conditions. The decomposition temperature of M30 was $221^{\circ} \mathrm{C}$ which is $46^{\circ} \mathrm{C}$ higher than the pure MIL-101, suggesting the PIM-1 matrix protected the MIL-101 structure from thermal decomposition and improved its thermal stability.

\subsection{High-pressure hydrogen storage and kinetics}

High-pressure hydrogen uptake measurements were taken on the pure materials (PIM-1 film, AX21, MIL-101) and a selection of composites (A20, A60, M10, M20, and M30) as representatives that covered low and high filler concentrations, as well as comparative data among the PIM-1/AX21,
PIM-1/PAF-1 and PIM-1/MIL-101 composites. The $\mathrm{H}_{2}$ isotherms at $77 \mathrm{~K}$, shown in Fig. 8a, d, illustrates fully-reversible adsorption processes for the selected samples. There was a clear increase in uptake with increasing AX21 and MIL101 content. Among the PIM-1/AX21, PIM-1/MIL-101 and PIM-1/PAF-1 composites, the highest excess $\mathrm{H}_{2}$ uptake of $3.1 \mathrm{wt} \%$ was achieved at $3.8 \mathrm{MPa}$ in the A60 (60 wt\%AX21 in PIM-1 composites) sample and the maximum uptakes increased with increasing filler content. This increase was lower than predicted from the rule of mixtures suggesting that the PIM-1 matrix blocks access to the filler, preventing full utilisation of the adsorptive capacity. It is also noted that MIL-101 composites showed the lowest uptake compared with AX21 and PAF-1 composites.

Modelling experimental excess data for hydrogen can offer important insights into the nature of hydrogen adsorption and the properties of materials. We assessed the total $\mathrm{H}_{2}$ uptake within the nanoporous composites and predicted the maximum capacities from high-pressure hydrogen adsorption measurements using our well-developed modelling and analysis method (Bimbo et al. 2013; Sharpe et al. 2015, 2013), the results of which are illustrated in Fig. 8b, e. The solid lines in Fig. 8b, e are the fitted excess uptakes and the dashed lines are the total amount of hydrogen that is contained in the materials. The resulting fits showed excellent agreement with the experimental data, with $\mathrm{R}^{2}$ values no lower than 0.998 for any sample, see Table S1. The total hydrogen uptakes that take into account both the excess hydrogen uptake and the compressed bulk gas were then estimated according to the fitting results. The total hydrogen storage capacity of A60 at $77 \mathrm{~K}$ reached $6.36 \mathrm{wt} \%$ at $10 \mathrm{MPa}$ (Table 2), which is 2.5 times higher than the capacity of PIM-1 alone and has great potential to meet the DoE hydrogen storage target (5.5 wt\% for a complete system) (Target Explanation Document 2017). The maximum theoretical hydrogen capacities of A60 and M30 were predicted by our model to be 9.35 and $7.23 \mathrm{wt} \%$, respectively; see Fig. $9 \mathrm{~b}$ and Table S3. Interestingly, when comparing the total uptakes at $10 \mathrm{MPa}$, the trend follows the rule of mixtures well (Fig. 9b). As the main driver of mass transport (pressure) increases, the adsorption uptake begins to reflect the mixture of the two components much more directly.

In addition to hydrogen uptake, the adsorbate density is another important parameter as the nature of hydrogen storage is about densification of hydrogen gas, and can be determined from the high-pressure hydrogen isotherm fitting. The adsorbed hydrogen densities in pure PIM-1 film, AX21 and MIL-101 were estimated to be 0.10, 0.079 and $0.082 \mathrm{~g} \mathrm{~cm}^{-3}$, which put the density of the adsorbed hydrogen within the region of solid-like hydrogen (the mass density of solid hydrogen (Ting et al. 2015; Bahadur et al. 2017) has been estimated at $\left.0.086 \mathrm{~g} \mathrm{~cm}^{-3}\right)$. This finding has been supported by direct observation via in-situ inelastic neutron 

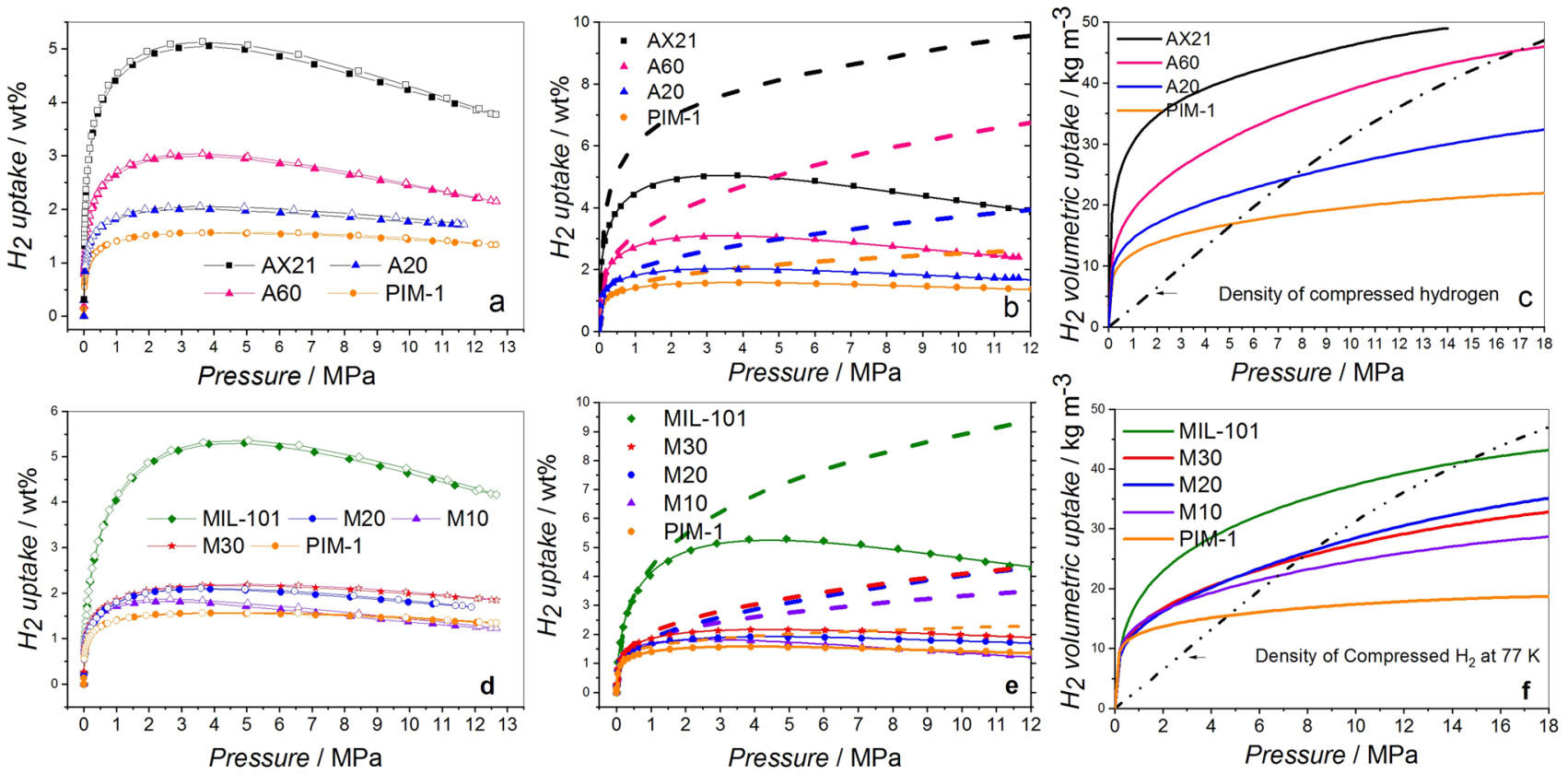

Fig. 8 a High-pressure $\mathrm{H}_{2}$ isotherms at $77 \mathrm{~K}$, b experimental $\mathrm{H}_{2}$ excess uptakes (symbols), fitting curves (solid lines), and calculated total hydrogen uptakes (dashed lines), and c Total volumetric hydrogen uptakes for pure PIM-1 film (orange circle), A20 (blue triangle), A60 (pink triangle) and pure AX21 powder (black square). Solid filled and open symbols represent adsorption and desorption branches, respectively; d High-pressure $\mathrm{H}_{2}$ isotherms at $77 \mathrm{~K}$, e
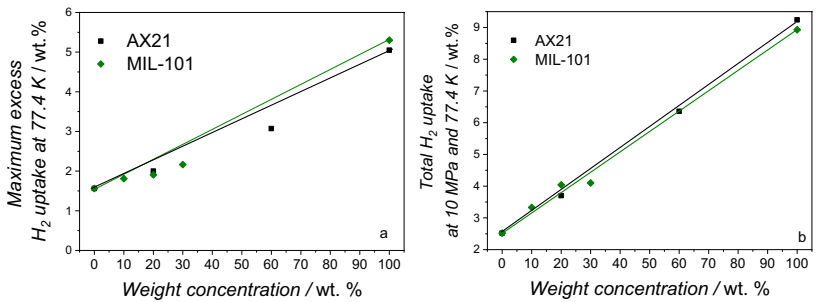

Fig. 9 Rule of mixture analyses for the high-pressure $\mathrm{H}_{2}$ isotherms on the PIM-1/MIL-101 and PIM-1/AX21 composites, examining a experimental highest $\mathrm{H}_{2}$ excess uptake at $77 \mathrm{~K}$, b total $\mathrm{H}_{2}$ uptake at $10 \mathrm{MPa}$ and $77 \mathrm{~K}$

scattering (Thommes et al. 2015). The adsorbate densities in the composites A20, A60, M20 and M30 fit well into the solid-like density region. In the case of bulk hydrogen gas at $77 \mathrm{~K}$, volumetric densities of 0.080 or $0.11 \mathrm{~g} \mathrm{~cm}^{-3}$ can be achieved by compressing the gas to pressures of 66 or $160 \mathrm{MPa}$, respectively, shown in Fig. S10. However, $160 \mathrm{MPa}$ is technically not feasible. By applying our materials, the same high gravimetric hydrogen densities can be obtained at much milder conditions (at up to $12 \mathrm{MPa}$ and $77 \mathrm{~K})$.

The volumetric hydrogen capacity of the PIM-1/AX21 and PIM-1/MIL-101 composite films and the volumetric experimental $\mathrm{H}_{2}$ excess uptakes (symbols), fitting curves (solid lines), and calculated total hydrogen uptakes (dashed lines), and f Total volumetric hydrogen uptakes for PIM-1 film (orange circle), MIL-101 powder (green diamond), M10 (purple triangle), M20 (blue circle), and M30 (red star). Filled and open symbols represent adsorption and desorption branches, respectively. (Color figure online)

density of compressed hydrogen gas without any adsorbent as a function of pressure at $77 \mathrm{~K}$ are illustrated in Fig. 8c, $\mathrm{f}$ to compare with the volumetric density within the adsorbents. PIM-1/AX21 composites, Fig. 8c, achieve higher volumetric capacities than similar PIM-1/MIL-101 composites, Fig. 8f. The relative storage efficiency for a high-pressure hydrogen tank either in the presence or in the absence of the adsorbents can be obtained from these two figures. For example, the use of pure PIM-1 film is beneficial over the absence of any adsorbent up to a pressure of $5 \mathrm{MPa}$. Beyond $5 \mathrm{MPa}$, simple compression of hydrogen becomes more advantageous since the volume displaced by the polymer becomes important. The benefit of using PIM-1/MIL-101 composites appears to extend up to a pressure of $\sim 8 \mathrm{MPa}$. The volumetric storage density of A60 was superior to that of compressed hydrogen at a pressure up to 17 MPa. PIM-1/ AX21 composites thus achieved high gravimetric and volumetric $\mathrm{H}_{2}$ densities simultaneously.

Another important set of parameters that has not been reported on porous polymer-based composites is hydrogen adsorption kinetics, which is related to the charging time of hydrogen on the composite system. Diffusion of hydrogen gas molecules can be very slow in micropores, compared to hydrogen adsorption and desorption. Therefore, diffusion of hydrogen is the rate-limiting factor in hydrogen adsorption 
in micropores and in penetration of hydrogen through membranes. Here, we have assessed hydrogen mass transfer coefficients (MTC) at a constant temperature (77 K) to provide a quantitative evaluation of the hydrogen adsorption kinetics for the three types of composite membranes. The mass transfer coefficients (MTC), $k$, in these materials were investigated using the Linear Driving Force (LDF) model (Glueckauf 1955). The higher the value of $k$, the faster the diffusion of hydrogen gas in the solid. The LDF model has been used extensively to evaluate macroscopic and non-equilibrium diffusion for gas adsorptive processes (Glueckauf 1955). The LDF model, shown in Eq. 2, has been applied to analyse the kinetics data for all high-pressure hydrogen isotherm points, to extract the mass transfer coefficients of hydrogen into PIM-1, AX21, MIL-101, A60 and M30 up to $12 \mathrm{MPa}$ at $77 \mathrm{~K}$.

For each pressure dosing step (on each $\mathrm{H}_{2}$ adsorption isotherm), the LDF was fitted to the kinetic data, and then the MTC, $k$, was determined from the individual fits. The model was assessed by the adjusted $R^{2}$, indicating a high-quality fitting with $R^{2} \geq 0.97$ for all fittings. Figure 10 shows the MTC as a function of pressure at $77 \mathrm{~K}$ for the PIM-1 film, AX21, A60, MIL-101 and M30. The PIM-1 based composite showed type I isotherm for all isotherm steps and fast hydrogen adsorption (equilibration) within $10 \mathrm{~min}$, as shown in Fig. S14. The MTC of AX21 and A30 decreased with increasing pressure until the excess adsorption reached the maximum uptake in the MTC range between 2 and $8 \mathrm{~min}^{-1}$.
This is because hydrogen molecules diffuse quickly on the surface of the pores at low pressure until the uptake reaches a maximum. The MTC of the PIM-1 film showed a constant, low value between 0.5 and $1 \mathrm{~min}^{-1}$ at pressures below $6 \mathrm{MPa}$ and then increased slightly at higher pressure. The MTC of A30 followed the same tendency as AX21 and indicated the combined feature of PIM- 1 and AX21. The MTC of the composites and additives stabilised in the 2.7-3.1 $\mathrm{min}^{-1}$ range beyond $6 \mathrm{MPa}$. It is concluded that adding $\mathrm{AX} 21$ or MIL-101 significantly increased the MTC of pure PIM-1 (Fig. $10 \mathrm{f}$ ), indicating the improvement of hydrogen adsorption kinetics by introducing AX21 and MIL-101 into the PIM-1 matrix.

\section{Conclusion}

This study has provided a detailed assessment of the development of porous polymer-based composite membranes for mobile hydrogen storage applications. The adsorbent composite membrane is advantageous over powders in terms of both safety, handling and practical manufacturing. An activated carbon, AX21, and a metal-organic framework, MIL-101, have been successfully incorporated into PIM-1 matrices to form PIM-1/AX21 and PIM-1/MIL-101 composite films of a range of filler compositions. The maximum weight concentrations of AX21 and MIL-101 were $60 \mathrm{wt} \%$
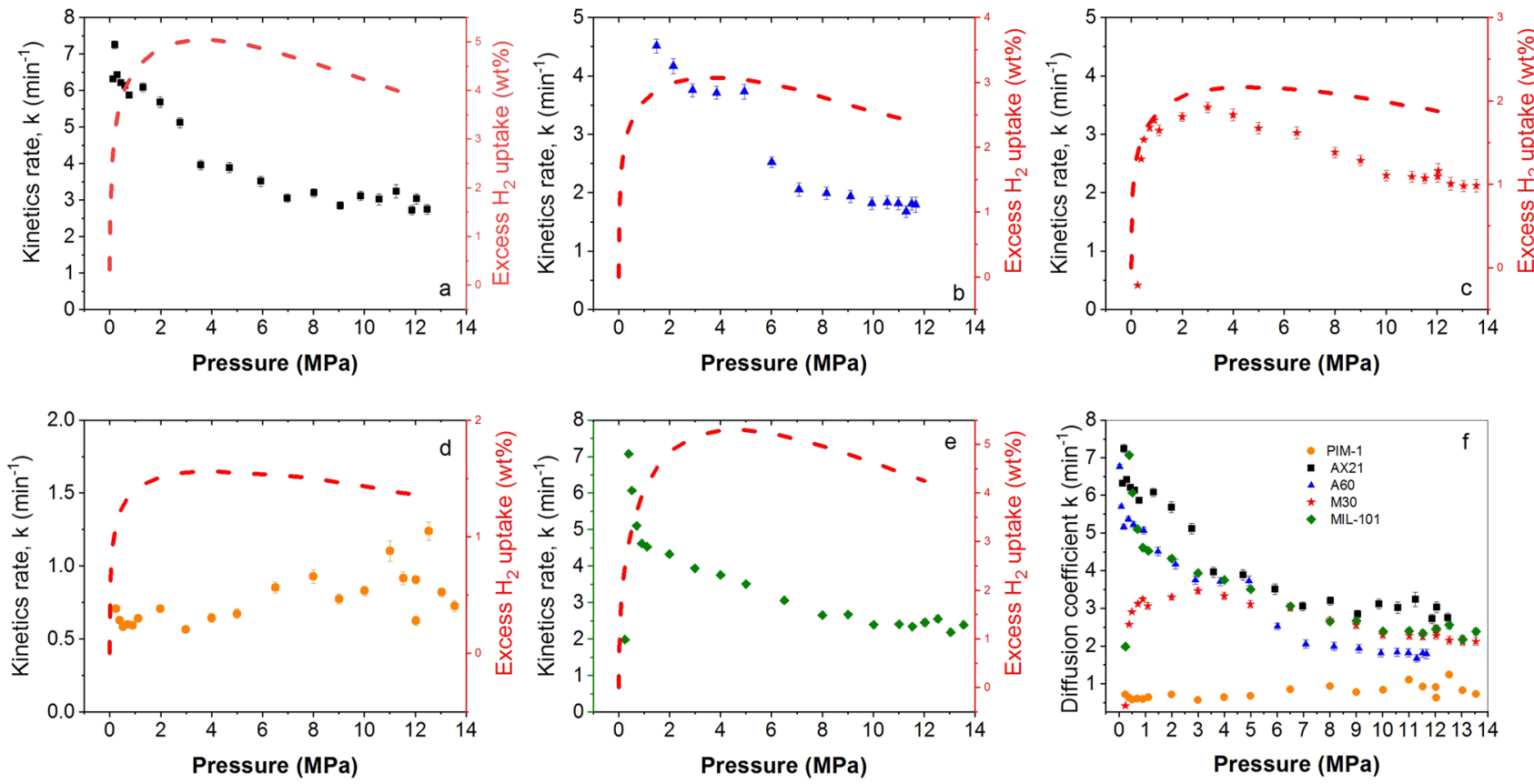

Fig. 10 Hydrogen adsorption kinetic rate, $k$ (symbols) and excess hydrogen uptakes (dashed lines) as a function of pressure at $77 \mathrm{~K}$ on a AX21, b A30, c M30, d PIM-1 film, e MIL-101, and f kinetic rate in one figure, indicating the improved MTC of the composites, A60 and M30, in comparison with the pure PIM-1 membrane 
and $40 \mathrm{wt} \%$, respectively, which still allowed the preparation of cohesive, mechanically stable and crack-free membranes.

The composite films, PIM-1/AX21 and PIM-1/MIL101, as well as PIM-1/PAF-1 from our previous study, have been fully characterised to evaluate their porosity, hydrogen storage properties and hydrogen adsorption kinetics. The BET surface area and its directly linked hydrogen storage properties all improve with increasing content of the nanoporous fillers. However, among the three types of composites, PIM-1/MIL-101 presents the lowest hydrogen storage capacity at $77 \mathrm{~K}$, below what is predicted based on the rule of mixtures, due to mass transfer limitations and pore blocking in the composite films. Activated carbon (AX21) containing composites show much better performances and the surface area of PIM-1/AX21 is in agreement with linear combinations of the surface area of their components, as predicted by the rule of mixtures. Hydrogen storage properties of PIM-1/AX21 composites also follow this trend. The total hydrogen storage capacity of A60 at $10 \mathrm{MPa}$ and $77 \mathrm{~K}$ reaches $6.36 \mathrm{wt} \%$, which is 2.5 times higher than PIM-1 alone. The composite system shows great potential to meet the US DOE target (5.5 wt\% for a complete system) through further development of the composite system and a system engineering design. Additionally, for the use as a hydrogen storage system in a fuel cell vehicle, the amount of hydrogen which can be delivered to the fuel cell is the key parameter. This usable capacity is defined as the amount of hydrogen released between a maximum tank pressure and a minimum back pressure for a fuel cell in a fuel cell vehicle (Schlichtenmayer and Hirscher 2016). We analyse the usable capacity for a hypothetic case of a maximum tank pressure of $5 \mathrm{MPa}$ and a system back pressure of $0.1 \mathrm{MPa}$ for PIM-1 film and A60 using the hydrogen adsorption experiment and the mathematical fitting results. The PIM-1 film and A60 release 1.45 and $2.48 \mathrm{wt} \%$ hydrogen at $77 \mathrm{~K}$ between $0.1 \mathrm{MPa}$ and $5 \mathrm{MPa}$, which are lower than the uptakes starting from vacuum conditions. It also needs to be noted that the usable capacities will be significantly improved if the temperature inside the tank increases due to the unloading process.

Kinetic studies of hydrogen adsorption on selected samples revealed that the addition of nanoporous additives significantly enhanced hydrogen diffusion in pores. Of the three types of fillers, composites with the activated carbon, AX21, exhibit the best mechanical properties and the best hydrogen storage properties from both low- and high- pressure hydrogen adsorption measurements.

We have clearly demonstrated that porous polymerbased composite materials offer great potential for hydrogen storage for mobile applications in a safer and more practical manner, especially for applications which requires a pressure up to $17 \mathrm{MPa}$. The hydrogen storage capacity and kinetics are significantly improved by introducing nanoporous fillers with extra high surface areas. Here, we have developed a comprehensive methodology to evaluate the gas adsorption performances of composite membranes, and we provide a strategy to select materials to be used as nanoporous fillers in such composite systems. More broadly, this study offers new insights into the design and characterisation of polymer-based composite membranes for versatile applications including gas adsorption and separation, carbon capture and utilisation, and waste gas treatment.

\section{Experimental section}

\subsection{Materials}

PIM-1 was prepared by adapting the synthesis method previously published by Budd et al. (2004).

AX21 activated carbon was sourced from Anderson Development Company Inc., Michigan, United States. It is synthesised using petroleum coke as the carbon precursor and activated through potassium hydroxide activation at $973 \mathrm{~K}$, a process patented by Standard Oil Company, Ohio, United States.

The chromium terephthalate metal-organic framework $\left[\mathrm{Cr}_{3} \mathrm{O}(\mathrm{OH})\left(\mathrm{H}_{2} \mathrm{O}\right)_{2}(\mathrm{bdc})_{3}\right]$, MIL-101 $(\mathbf{C r})$, was prepared following a published procedure (Jiang et al. 2012; Leng et al. 2016).

Synthesis of PAF-1 and all analysis and data of PIM-1/ PAF-1 composites have been reported in our previous publication, which will be used as a benchmark in this work (Rochat et al. 2017).

PIM-1 based AX21 and MIL-101 composites were solvent cast using a previously described protocol (Rochat et al. 2017). Briefly, the solution of PIM-1 and suspensions of the fillers were prepared separately in chloroform to form $2 \mathrm{wt} \%$ mixtures that were stirred for $24 \mathrm{~h}$ at room temperature. After mixing the solutions with each other to achieve the desired gravimetric proportions of filler and PIM-1, the suspensions were stirred for another $24 \mathrm{~h}$ and cast into a $6 \mathrm{~cm}$ glass Petri dish (for adsorption analysis) and $20 \mathrm{~cm}$ Petri dish (for mechanical testing), covered and left to slowly evaporate over two weeks. The detailed calculation and the mass for membrane casting can be found in the supplementary information. The formed composite films were then dried under vacuum at $353 \mathrm{~K}$ for $8 \mathrm{~h}$. Finally, the composite films were peeled off from the Petri dish for measurement and testing. All samples were degassed at $353 \mathrm{~K}$ for $8 \mathrm{~h}$ under a vacuum of $0.1 \mathrm{mPa}$ in order to remove moisture and adsorbed gases from the surface before any gas adsorption measurement. 


\subsection{Characterisation}

Scanning electron microscopy (SEM) analysis of the samples to study their morphology was performed using a Field Emission-SEM (FESEM), JEOL JSM-6301F. The samples were coated with chromium via sputtering, using a Quorum Q150TS. Cross-sections of membrane samples were prepared by freeze fracturing after immersion in liquid nitrogen. The fractured samples were mounted on stubs using two-side conductive carbon tape. Particle size was analysed using ImageJ software.

Surface areas were determined by BET analysis with $\mathrm{N}_{2}$ isotherms at $77 \mathrm{~K}$ using a Micrometritics 3Flex volumetric gas sorption analyser $\left(p / p_{0}\right.$ range used for the BET calculation: $0.05-0.3)$. Total pore volumes were calculated from the nitrogen uptake at $p / p_{0}=0.97$, and pore size distributions were estimated using non-local density functional theory (NLDFT) provided with the MicroActive data analysis software using slit-pore model for $\mathrm{N}_{2}$ at $77 \mathrm{~K}$ and $\mathrm{CO}_{2}$ at $273 \mathrm{~K}$.

The skeletal density, which is the volume of the sample excluding the space available for the probe gas divided by the sample's mass, was measured at room temperature by a helium pycnometer (Micromeritics AccuPyc 1330, Micromeritics Instrument Corporation, Norcross, GA, USA). Prior to the pycnometry measurement, samples were degassed for $8 \mathrm{~h}$ at $80{ }^{\circ} \mathrm{C}$ in a vacuum oven. The total pore volume and the skeletal density were then used to determine bulk density of materials using Eq. 1.

$\rho_{\text {bulk }}=\frac{1}{\frac{1}{\rho_{\text {skeletal }}}+v_{\mathrm{t}}}$

where $\rho_{\text {bulk }}$ is the bulk density of sample, $\mathrm{g}^{-1} ; \rho_{\text {skeletal }}$ is the skeletal density measured from helium pycnometry, $\mathrm{g}^{-1}$; and $v_{t}$ is the total pore volume determined from $\mathrm{N}_{2}$ isotherm at $77 \mathrm{~K}, 1 \mathrm{~g}^{-1}$.

$\mathrm{CO}_{2}$ adsorption up to $2 \mathrm{MPa}$ at $273 \mathrm{~K}$ was carried out on an Intelligent Gravimetric Analyzer (IGA-002) from Hiden Isochema, Warrington, UK. The measured $\mathrm{CO}_{2}$ isotherms data were imported to the MicroActive data analysis software (Micromeritics) for pore size distribution analysis using the slit-pore model for $\mathrm{CO}_{2}$ at $273 \mathrm{~K}$ (NLDFT).

Low-pressure hydrogen (up to $0.1 \mathrm{MPa}$ ) adsorption measurements at $77 \mathrm{~K}$ were carried out using a 3 Flex instrument from Micromeritics. The high-pressure hydrogen isotherms (up to $12 \mathrm{MPa}$ ) were collected at equilibrium in a Hiden HTP-1 volumetric sorption analyser using a liquid nitrogen immersion Dewar for temperature control (Hiden Isochema, Warrington, UK). Prior to hydrogen uptake measurements, the samples $(\sim 150 \mathrm{mg})$ were degassed in situ at $353 \mathrm{~K}$ for $8 \mathrm{~h}$ under a vacuum of $0.1 \mathrm{mPa}$ in order to remove moisture and adsorbed gases from the surface. The hydrogen isotherms are fully reproducible and reversible within $\pm 0.3 \%$ of measured amounts adsorbed. The nonlinear fitting and calculations were carried out using a Levenberg-Marquardt method via OriginPro 2018. The isotherms were analysed and modelled using our previously reported methodology (Rochat et al. 2017; Sharpe et al. 2015) in order to estimate the total hydrogen adsorption capacity and the adsorbed $\mathrm{H}_{2}$ density, which were listed in the supporting information, along with details of the modelling.

The Hiden HTP-1 instrument also records the realtime uptake, temperature and pressure of the sample while acquiring hydrogen isotherms. The kinetics data-uptake as a function of time- were used to calculate the hydrogen adsorption kinetic parameter using the linear-driving force (LDF) equation. The LDF model for adsorption is described by Eq. 2 (Glueckauf 1955).

$\frac{n_{t^{\prime}}-n_{1}}{n_{2}-n_{1}}=1-\exp \left(-k t^{\prime}\right)$ and $t^{\prime}=t-t_{1}$

The boundary conditions can be described as:

(i) $n_{\mathrm{t}^{\prime}}=n_{1}$ at $t=t_{1}$ yields $\frac{n_{\mathrm{t}^{\prime}}-n_{1}}{n_{2}-n_{1}}=0$

(ii) $n_{\mathrm{t}^{\prime}}=n_{2}$ at $t \rightarrow \infty$ yields $\frac{n_{t^{\prime}}-n_{1}}{n_{2}-n_{1}}=1$

where $n$ is amount adsorbed, mmol; $\mathrm{t}$ is time in $\min , n_{1}$ is the initial hydrogen amount in mmol at $t=t_{1} ; n_{2}$ is the equilibrium amount, mmol; $n_{t^{\prime}}$ is amount adsorbed in mmol at time $t^{\prime}$ and $\mathrm{k}$ is the mass transfer coefficient (MTC) for the LDF model, $\min ^{-1}$. The fitting of the kinetic data was performed using the non-linear fitting tool in Origin Pro 2018. This was applied for every pressure dosing step in $\mathrm{H}_{2}$ isotherms. The examples of the first dosing step and the LDF fittings are shown in Fig. S14. The hydrogen uptakes as a function of time for all the isotherm points were recorded by the Hiden HTP-1 instrument, shown in Figs. S11, S12 and S13.

Hydrogen gas used for all measurement is BIP PLUS grade high-purity $99.999996 \%$ hydrogen from Air Products. The gas adsorption temperature was maintained at $77.4 \pm 0.1 \mathrm{~K}$. The pressure was monitored with an accuracy of $\pm 0.02 \%$. Each gas dosing was followed by the equilibration time of at least $20 \mathrm{~min}$. Helium gas used for pycnometer, HTP-1 and 3Flex is Grade A helium from BOC.

\subsection{Mechanical properties}

Pure polymer films were manufactured by dissolving $1.22 \mathrm{~g}$ PIM-1 in $40 \mathrm{ml}$ chloroform and pouring the solution into a large $20 \mathrm{~cm}$ Petri dish where it was left to evaporate for $48 \mathrm{~h}$. To prepare composite films, the metal-organic framework MIL-101 and activated carbon AX21 powders were separately stirred with a small amount of chloroform for $24 \mathrm{~h}$ and added to PIM-1/chloroform solution to then be 
stirred for another $24 \mathrm{~h}$ in room temperature. Different ratios of MIL-101: PIM-1 and AX21: PIM-1 mixtures were prepared to obtain $10 \mathrm{wt} \%, 20 \mathrm{wt} \%, 30 \mathrm{wt} \%, 40 \mathrm{wt} \%$ and $50 \mathrm{wt} \%$ solutions. PIM-1/MIL-101 solutions were poured into a Petri dish and left to evaporate for $48 \mathrm{~h}$. PIM-1/AX21 films were left to evaporate in a closed desiccator for period of 2 weeks. After evaporation, all films were dried under vacuum at $353 \mathrm{~K}$ for $8 \mathrm{~h}$ to eliminate solvent residues. For mechanical testing purposes, rectangular samples were cut according to BS EN ISO 527-3:1996 standard (1/2 of Specimen type 2) (33). Preliminary tests were run to confirm that the decreased dimensions of specimens did not influence the mechanical characterisation results. The thickness of the samples was assessed using a Mitutoyo 227-211 Absolute Digimatic Micrometer with $\pm 0.001 \mathrm{~mm}$ measurement accuracy and measuring force adjustment.

Uniaxial tensile testing was performed on a Instron 3369 instrument with a $50 \mathrm{~N}$ static load cell and pneumatic clamps with a quasi-static strain rate of $2 \mathrm{~mm} / \mathrm{min}$. Values of force and clamps extension were recorded. Yielding and ultimate stress and strains were calculated and Young's moduli were determined from the linear stress-strain curve. At least nine samples were tested for pure PIM-1 and each composite film.

Acknowledgements This work was financially supported by the UK Engineering and Physical Sciences Research Council (EPSRC) via SUPERGEN Grants Nos. EP/K021109/1 and EP/L018365/1, and the EPSRC Doctoral Training Centre in Sustainable Chemical Technologies, under Grant No. EP/G03768X/1.

\section{Compliance with ethical standards}

Conflict of interest There are no conflicts to declare.

Open Access This article is distributed under the terms of the Creative Commons Attribution 4.0 International License (http://creativeco mmons.org/licenses/by/4.0/), which permits unrestricted use, distribution, and reproduction in any medium, provided you give appropriate credit to the original author(s) and the source, provide a link to the Creative Commons license, and indicate if changes were made.

\section{References}

Bahadur, J., Contescu, C.I., Ramirez-Cuesta, A.J., Mamontov, E., Gallego, N.C., Cheng, Y., Daemen, L.L., Melnichenko, Y.B.: Properties of immobile hydrogen confined in microporous carbon. Carbon 117, 383-392 (2017)

Bimbo, N., Ting, V.P., Sharpe, J.E., Mays, T.J.: Analysis of optimal conditions for adsorptive hydrogen storage in microporous solids. Colloids Surf. A 437, 113-119 (2013)

Bimbo, N., Xu, W., Sharpe, J.E., Ting, V.P., Mays, T.J.: High-pressure adsorptive storage of hydrogen in MIL-101 $(\mathrm{Cr})$ and AX-21 for mobile applications: cryocharging and cryokinetics. Mater. Des. 89, 1086-1094 (2016)

Broom, D.P., Webb, C.J., Hurst, K.E., Parilla, P.A., Gennett, T., Brown, C.M., Zacharia, R., Tylianakis, E., Klontzas, E., Froudakis, G.E., Steriotis, T.A., Trikalitis, P.N., Anton, D.L., Hardy, B.,
Tamburello, D., Corgnale, C., van Hassel, B.A., Cossement, D., Chahine, R., Hirscher, M.: Outlook and challenges for hydrogen storage in nanoporous materials. Appl. Phys. A 122(3), 151 (2016)

Budd, P.M., Elabas, E.S., Ghanem, B.S., Makhseed, S., McKeown, N.B., Msayib, K.J., Tattershall, C.E., Wang, D.: Solution-processed, organophilic membrane derived from a polymer of intrinsic microporosity. Adv. Mater. 16(5), 456-459 (2004a)

Budd, P.M., Ghanem, B.S., Makhseed, S., McKeown, N.B., Msayib, K.J., Tattershall, C.E.: Polymers of intrinsic microporosity (PIMs): robust, solution-processable, organic nanoporous materials. Chem. Commun. 2, 230-231 (2004b)

Férey, G., Mellot-Draznieks, C., Serre, C., Millange, F., Dutour, J., Surblé, S., Margiolaki, I.: A chromium terephthalate-based solid with unusually large pore volumes and surface area. Science 309(5743), 2040 (2005)

Ghalei, B., Sakurai, K., Kinoshita, Y., Wakimoto, K., Isfahani, A.P., Song, Q., Doitomi, K., Furukawa, S., Hirao, H., Kusuda, H., Kitagawa, S., Sivaniah, E.: Enhanced selectivity in mixed matrix membranes for $\mathrm{CO}_{2}$ capture through efficient dispersion of amine-functionalized MOF nanoparticles. Nature Energy 2, 17086 (2017)

Glueckauf, E.: Theory of chromatography. Part 10.-Formulae for diffusion into spheres and their application to chromatography. Trans. Faraday Soc. 51(0), 1540-1551 (1955)

Gogotsi, Y., Portet, C., Osswald, S., Simmons, J.M., Yildirim, T., Laudisio, G., Fischer, J.E.: Importance of pore size in high-pressure hydrogen storage by porous carbons. Int. J. Hydrogen Energy 34(15), 6314-6319 (2009)

Jiang, D., Keenan, L.L., Burrows, A.D., Edler, K.J.: Synthesis and postsynthetic modification of MIL-101(Cr)- $\mathrm{NH}_{2}$ via a tandem diazotisation process. Chem. Commun. 48(99), 12053-12055 (2012)

Kamata, K., Iyoda, T.: Nanocylinder array structures in block copolymer thin films. In: Hosono, H., Mishima, Y., Takezoe, H., MacKenzie, K.J.D., MacKenzie, K., Mishima, Y., Takezoe, H. (eds.) Nanomaterials, pp. 171-223. Elsevier Science Ltd, Oxford (2006)

L. British Standards Institution, Plastics. Determination of Tensile Properties. Test Conditions for Moulding and Extrusion Plastics, BSI, BS EN ISO 527-31996

Leng, K., Sun, Y., Li, X., Sun, S., Xu, W.: Rapid synthesis of metalorganic frameworks MIL-101(CR) without the addition of solvent and hydrofluoric acid. Cryst. Growth Des. 16(3), 1168-1171 (2016)

Lin, R., Ge, L., Hou, L., Strounina, E., Rudolph, V., Zhu, Z.: Mixed matrix membranes with strengthened MOFs/polymer interfacial interaction and improved membrane performance. ACS Appl. Mater. Interfaces. 6(8), 5609-5618 (2014)

Louis, P., Gokhale, A.M.: Computer simulation of spatial arrangement and connectivity of particles in three-dimensional microstructure: application to model electrical conductivity of polymer matrix composite. Acta Mater. 44(4), 1519-1528 (1996)

Low, Z.-X., Budd, P.M., McKeown, N.B., Patterson, D.A.: Gas permeation properties, physical aging, and its mitigation in high free volume glassy polymers. Chem. Rev. 118(12), 5871-5911 (2018)

McKeown, N.B., Budd, P.M.: Polymers of intrinsic microporosity (PIMs): organic materials for membrane separations, heterogeneous catalysis and hydrogen storage. Chem. Soc. Rev. 35(8), 675-683 (2006)

Naeem, A., Ting, V.P., Hintermair, U., Tian, M., Telford, R., Halim, S., Nowell, H., Holynska, M., Teat, S.J., Scowen, I.J., Nayak, S.: Mixed-linker approach in designing porous zirconium-based metal-organic frameworks with high hydrogen storage capacity. Chem. Commun. 52(50), 7826-7829 (2016)

Noguera-Díaz, A., Bimbo, N., Holyfield, L.T., Ahmet, I.Y., Ting, V.P., Mays, T.J.: Structure-property relationships in metal-organic frameworks for hydrogen storage. Colloids Surf. A 496, 77-85 (2016) 
Polak-Kraśna, K., Dawson, R., Holyfield, L.T., Bowen, C.R., Burrows, A.D., Mays, T.J.: Mechanical characterisation of polymer of intrinsic microporosity PIM-1 for hydrogen storage applications. J. Mater. Sci. 52(7), 3862-3875 (2017)

Rochat, S., Polak-Krasna, K., Tian, M., Holyfield, L.T., Mays, T.J., Bowen, C.R., Burrows, A.D.: Hydrogen storage in polymer-based processable microporous composites. J. Mater. Chem. A 5(35), 18752-18761 (2017)

Rochat, S., Polak-Kraśna, K., Tian, M., Mays, T.J., Bowen, C.R., Burrows, A.D.: Assessment of the long-term stability of the polymer of intrinsic microporosity PIM-1 for hydrogen storage applications, Int. J. Hydrog. Energy 44, 332-337 (2018)

Schlichtenmayer, M., Hirscher, M.: The usable capacity of porous materials for hydrogen storage. Appl. Phys. A 122(4), 379 (2016)

Sharpe, J.E., Bimbo, N., Ting, V.P., Burrows, A.D., Jiang, D., Mays, T.J.: Supercritical hydrogen adsorption in nanostructured solids with hydrogen density variation in pores. Adsorption 19(2), 643-652 (2013)

Sharpe, J.E., Bimbo, N., Ting, V.P., Rechain, B., Joubert, E., Mays, T.J.: Modelling the potential of adsorbed hydrogen for use in aviation. Microporous Mesoporous Mater. 209, 135-140 (2015)

Thommes, M.: Physical adsorption characterization of nanoporous materials. Chem. Ing. Tec. 82(7), 1059-1073 (2010)

Thommes, M., Kaneko, K., Neimark Alexander, V., Olivier James, P., Rodriguez-Reinoso, F., Rouquerol, J., S.W. Sing Kenneth: Physisorption of gases, with special reference to the evaluation of surface area and pore size distribution (IUPAC Technical Report). Pure Appl. Chem. 87, 1051 (2015)

Tian, M., Batty, S., Shang, C.: Synthesis of nanostructured carbons by the microwave plasma cracking of methane. Carbon 51, 243-248 (2013)

Ting, V.P., Ramirez-Cuesta, A.J., Bimbo, N., Sharpe, J.E., NogueraDiaz, A., Presser, V., Rudic, S., Mays, T.J.: Direct evidence for solid-like hydrogen in a nanoporous carbon hydrogen storage material at supercritical temperatures. ACS Nano 9(8), 8249-8254 (2015)

Wang, Z.G., Liu, X., Wang, D., Jin, J.: Troger's base-based copolymers with intrinsic microporosity for $\mathrm{CO}_{2}$ separation and effect of Troger's base on separation performance. Polym. Chem. 5(8), 2793-2800 (2014)

Yushin, G., Dash, R., Jagiello, J., Fischer, J.E., Gogotsi, Y., Carbidederived carbons: effect of pore size on hydrogen uptake and heat of adsorption. Adv. Funct. Mater. 16(17), 2288-2293 (2006)

Target Explanation Document: Onboard Hydrogen Storage for LightDuty Fuel Cell Vehicles, Accesssed on 26/06/2018 (2017)

Publisher's Note Springer Nature remains neutral with regard to jurisdictional claims in published maps and institutional affiliations. 